\title{
Pressurised aerosol deposition in the human lung with and without an "open" spacer device
}

\author{
S P NEWMAN, A R CLARK, N TALAEE, S W CLARKE \\ From the Department of Thoracic Medicine, Royal Free Hospital and School of Medicine, London, and the \\ Pharmaceutical Division, Fisons PLC, Loughborough
}

ABSTRACT A radiotracer technique has been used to assess aerosol delivery from a pressurised metered dose inhaler, used both with and without a $10 \mathrm{~cm}$ cylindrical spacer attachment (Syncroner), which has an open section in its upper surface. The radionuclide technetium- $99 \mathrm{~m}\left({ }^{99 \mathrm{~m}} \mathrm{Tc}\right)$ was added to sodium cromoglycate in a canister (Intal inhaler; $1 \mathrm{mg} / \mathrm{puff}$ ); in vitro studies with a multistage liquid impinger showed that the radiolabel acted as a marker for the presence of drug over a wide range of particle sizes. Ten healthy volunteers were studied after they had inhaled from (1) a metered dose inhaler alone (slow inhaled flow rate, about $25 \mathrm{l} / \mathrm{min}$ ); (2) metered dose inhaler plus spacer (slow flow rate); and (3) metered dose inhaler plus spacer (fast inhaled flow rate, about $100 \mathrm{l} / \mathrm{min}$ ). Inhalation was coordinated with firing the spray and was followed by 10 seconds' breath holding. With the metered dose inhaler alone a mean $11.0 \%$ (SEM 1.4\%) of the dose reached the lungs, compared with significantly higher doses for slow $(16 \cdot 1 \%(2 \cdot 2 \%))$ and fast $(13 \cdot 3 \%(1 \cdot 7 \%))$ inhalations through the spacer. The distribution pattern within the lungs was significantly more peripheral after slow inhalation. Oropharyngeal deposition was halved by the spacer. The open spacer should teach patients good coordination and delivers more aerosol to the lungs than a correctly used metered dose inhaler.

\section{Introduction}

Pressurised metered dose inhalers are used to deliver the prophylactic agent sodium cromoglycate, in addition to the more commonly used bronchodilators and topical corticosteroids. ${ }^{\prime}$ Many patients have a poor inhaler technique, however, and may fail to derive full benefit from these drugs. ${ }^{2}$ Poor coordination between firing the metered dose inhaler and inhalation is a major problem, ${ }^{34}$ which may be overcome in various ways - for example, by using a nebuliser, dry powder inhaler, or breath actuated metered dose inhaler. ${ }^{5}$ Various metered dose inhaler training aids have been described, often providing the patient with aural or visual feedback to indicate the correct time to fire the metered dose inhaler. ${ }^{6}$ A spacer device with an open section in its upper surface (Syncroner, fig 1), intended to act as a training aid, was recently described for use with a sodium cromoglycate inhaler (Intal inhaler). ${ }^{7}$ If the patient fails to coordi-

Address for reprint requests: Dr S P Newman, Department of Thoracic Medicine, Royal Free Hospital, London NW3 2QG.

Accepted 13 June 1989 nate, a cloud will be seen to emerge from the open part of the spacer; the patient can then adjust the inhalation manoeuvre until little or no aerosol cloud is seen. This paper describes the use of a simple radiolabelling method to determine pressurised aerosol deposition both with a standard metered dose inhaler and with the "open" spacer device and compares the relative efficiency of fast and slow inhalation through the spacer.

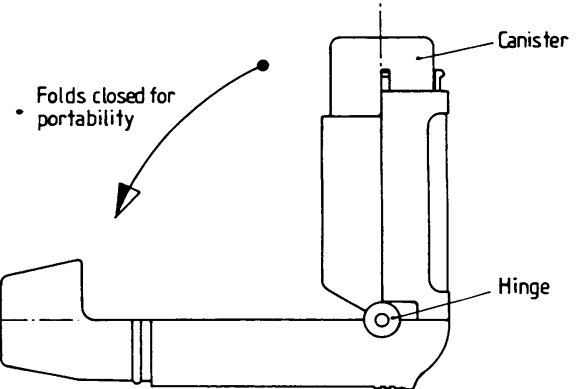

Fig 1 Open spacer device (Syncroner, Fisons PLC). 
Methods

\section{RADIOTRACER METHOD}

A radiotracer method based on that described by Kohler et $a l^{8}$ was used to label the contents of the metered dose inhalers. About $3 \mathrm{GBq}(81 \mathrm{mCi})$ technetium-99m $\left.{ }^{99 m} \mathrm{Tc}\right)$ as pertechnetate was eluted from a radionuclide generator (Amersham International) in a volume of $4 \mathrm{ml}$. Two drops of ammonia and two drops of tetraphenylarsonium chloride (TPAC, $1 \%$ solution) were added, followed by $4 \mathrm{ml}$ chloroform. ${ }^{9}$ These were mixed thoroughly in an ultrasonic shaker and then passed through a phase separating filter paper (Whatman $1 \mathrm{~s}^{\mathrm{p}}$ ). About $1.5 \mathrm{GBq}{ }^{99 \mathrm{~m}} \mathrm{Tc}$ dissolved in chloroform was collected in an empty aluminium canister, and the chloroform evaporated by compressed air. A sealed canister containing $112 \mathrm{mg}$ sodium cromoglycate (Intal, Fisons PLC) in $5.6 \mathrm{ml}$ chlorofluorocarbon propellants (Freon-12 and Freon-114 in the ratio 2:3) was cooled to below $-60^{\circ} \mathrm{C}$ and opened with a pipe cutter. The contents were transferred to the canister containing the radiolabel, a metering valve was added, and the canister was immediately sealed by a crimper (Aero-Fill Ltd). The labelled canister was then vibrated in an ultrasonic shaker for five minutes and the valve primed by discarding the first five metered doses into a filter. Each subsequent metered dose delivered $1 \mathrm{mg}$ sodium cromoglycate plus about $15 \mathrm{MBq}{ }^{99 \mathrm{~m}} \mathrm{Tc}$ in $50 \mu \mathrm{l}$ propellant.

\section{EVALUATION OF RADIOTRACER METHOD}

The extent to which the distribution of the ${ }^{99 m} \mathrm{Tc}$ label resembled that of the drug among different droplet size bands was examined with a multistage liquid impinger similar to that described by Bell et al. ${ }^{10}$ The impinger comprised four impaction stages to trap droplets of different sizes, a $90^{\circ}$ bend or "throat" placed between the inhaler and stage 1 , and a filter between stage 4 and a suction pump that drew air through the impinger at $60 \mathrm{l} / \mathrm{min}$. Material collected on the throat, stage 1 , and stage 2 is composed of coarse droplets, such as are likely to be deposited in the upper airways, while droplets penetrating to stages 3 and 4 are predominantly under $7 \mu \mathrm{m}$ in diameter and hence more likely to be inhaled into the lungs. ${ }^{10}$

Twenty metered doses from four unlabelled metered dose inhalers were delivered to the impinger with the actuator or actuator plus spacer placed at the entrance to the throat. The actuator, spacer, throat, impaction stages, and filter were washed with trichlorofluoromethane to dissolve the surface active agent (sorbitan trioleate). The washings were filtered individually through $0.45 \mu \mathrm{m}$ membrane filters to trap the drug particles. After drying, both the membrane filters and the different parts of the impinger system were washed with distilled water and quantities of drug determined by ultraviolet spectrophotometer (Pye Unicam) at a wavelength of $326 \mathrm{~nm}$. The contents of the same sodium cromoglycate metered dose inhalers were then radiolabelled as described above, and the impinger measurements repeated. The radioactivity on actuator, spacer, throat, impaction stages, and filter was determined by a General Electric $400 \mathrm{~T}$ gamma camera connected on line to a Nodecrest data processing system, regions of interest being drawn round each zone. After 48 hours' decay the amount of sodium cromoglycate at each location within the impinger system was determined by spectrophotometric assay.

\section{SUBJECTS}

Radioaerosol studies were performed in 10 normal volunteers (six male, four female), whose ages ranged from 20 to 47 years. All the subjects were free of respiratory symptoms; forced expiratory volume in one second $\left(\mathrm{FEV}_{1}\right)$ ranged from $82 \%$ to $108 \%$ predicted, and maximum expiratory flow rate at $50 \%$ forced vital capacity from $64 \%$ to $115 \%$ predicted. Six subjects were current smokers (range 1-5 pack years), though four smoked less than five cigarettes daily. Each subject gave informed consent in writing, and the studies were approved by both the ethical practices subcommittee of the hospital and the Administration of Radioactive Substances Advisory Committee.

\section{STUDY PROTOCOL}

Three radioaerosol studies were performed on three study days in a randomised order: (1) inhalation from metered dose inhaler alone, with aerosol inhaled at a slow flow rate (about $25 \mathrm{l} / \mathrm{min}$ ); (2) inhalation from metered dose inhaler plus open spacer (Syncroner), with a slow inhaled flow rate; (3) inhalation from metered dose inhaler plus open spacer, with a fast inhaled flow rate (about $100 \mathrm{l} / \mathrm{min}$ ).

In each study the metered dose inhaler was placed in a shielded Perspex jig containing a solenoid, which was used by an observer to actuate a single dose from the metered dose inhaler while the subject took a deep inhalation from functional residual capacity to total lung capacity, with the lips closed round the inhaler mouthpiece. This was followed by 10 seconds' breath holding followed by exhalation via a filter (Inspiron 002290). The inhalation technique for the metered dose inhaler alone has been shown to optimise delivery to the lungs. " During inhalation from the spacer a specially designed hood was placed over the open section, and air was drawn through the hood at 10 $1 /$ min into a further filter to collect any aerosol lost from the open part of the spacer; in vitro tests showed that withdrawing air from the open section of the spacer at this rate did not alter the amount of drug available from the spacer mouthpiece. Inhalation flow 
rate and volume were measured by respiratory inductance plethysmography (Respitrace Corporation).

Immediately after inhalation, a posterior-anterior view of the lungs and stomach (100 seconds) and a right lateral view of the oropharynx ( 30 seconds) were obtained by gamma camera. Counts were corrected for attenuation of gamma rays by tissue during their passage to the detector ${ }^{12}$ with correction factors that depended on each subject's chest dimensions. On a single occasion subjects inhaled krypton-81m $\left({ }^{81 \mathrm{~m}} \mathrm{Kr}\right.$ ) gas from a generator (Medical Research Council Cyclotron Unit) to obtain a posterior-anterior ventilation scan. Subsequently, the $20 \%$ contour of the ventilation scan was superimposed on the aerosol image to delineate the lung edges on the latter, and regions of interest ${ }^{12}$ were drawn on the aerosol view around central, intermediate, and peripheral lung zones (fig 2). Activity detected in mouth, pharynx, oesophagus, and stomach was added and attributed to aerosol deposited in the oropharynx. The percentages of the dose deposited on the actuator and spacer and that lost from the open part of the spacer and recovered from the exhaled air filter were determined by comparing count rates with those from a calibration dose actuated into a beaker of water, two small scintillation probes being used. That part of the dose not accounted for in these samples was assumed to be in the subject and was divided into lung and oropharyngeal fractions according to the gamma camera counts.

The radiation dose to the lungs from three inhalations of ${ }^{99 \mathrm{~m}} \mathrm{Tc}$ and a single inhalation of ${ }^{81 \mathrm{~m}} \mathrm{Kr}$ was estimated as $200 \mu \mathrm{Gy}$ ( $20 \mathrm{mrad})$.

\section{STA TISTICAL ANALYSIS}

Deposition data from the three studies were compared by the Friedman non-parametric analysis of variance by ranks; where a result was significant $(p<0.05)$ pairs of data were tested by the multiple comparison test described by Conover. ${ }^{13}$

\section{Results}

EVALUATION OF RADIOAEROSOL TECHNIQUE

The distributions of labelled drug, unlabelled drug, and radioactivity within the impinger system from the metered dose inhaler alone and from the inhaler with the spacer were virtually the same (table 1). The major sites of both drug and radiolabel recovery were on the apparatus and in the throat; similar amounts of drug and radiolabel were contained in "respirable" droplets penetrating to stages 3 and 4 . The coefficient of variation of the count rates of metered doses actuated into beakers containing water was $4.5 \%$.

IN VIVO STUDIES

The distribution of radioaerosol between lungs, oro-
Table 1 Mean (SD) distributions of radiolabel and sodium cromoglycate, expressed as percentages of total recovery, with a multistage liquid impinger system

\begin{tabular}{|c|c|c|c|c|c|c|}
\hline & \multicolumn{4}{|c|}{ Labelled $M D I(n=4)$} & \multirow{2}{*}{\multicolumn{2}{|c|}{$\begin{array}{l}\text { Unlabelled } \\
M D I(n=4 \\
\text { Drug }\end{array}$}} \\
\hline & Radi & olabel & Drug & & & \\
\hline $\begin{array}{l}\text { MDI alone } \\
\text { Actuator } \\
\text { Throat } \\
\text { Stage } 1 \\
\text { Stage } 2 \\
\text { Stage } 3 \\
\text { Stage } 4 \\
\text { Filter }\end{array}$ & $\begin{array}{r}11.8 \\
51.0 \\
7.9 \\
7.4 \\
12.4 \\
9.4 \\
0.1\end{array}$ & $\begin{array}{l}(0.7) \\
(1.9) \\
(3 \cdot 7) \\
(1.8) \\
(2.5) \\
(4 \cdot 1) \\
(0.1)\end{array}$ & $\begin{array}{r}10.1 \\
53.2 \\
7.0 \\
8.0 \\
12.4 \\
9.0 \\
0.2\end{array}$ & $\begin{array}{l}(2 \cdot 9) \\
(5 \cdot 7) \\
(2 \cdot 3) \\
(1 \cdot 5) \\
(3 \cdot 8) \\
(4 \cdot 5) \\
(0 \cdot 1)\end{array}$ & $\begin{array}{r}11 \cdot 5 \\
54 \cdot 2 \\
6.4 \\
7 \cdot 2 \\
12.8 \\
7.9 \\
0.1\end{array}$ & $\begin{array}{l}(3 \cdot 1) \\
(2.9) \\
(1 \cdot 6) \\
(2 \cdot 9) \\
(2 \cdot 7) \\
(2 \cdot 6) \\
(0.1)\end{array}$ \\
\hline $\begin{array}{l}\text { MDI plus spacer } \\
\text { Actuator/spacer } \\
\text { Throat } \\
\text { Stage } 1 \\
\text { Stage } 2 \\
\text { Stage } 3 \\
\text { Stage } 4 \\
\text { Filter }\end{array}$ & $\begin{array}{r}31.4 \\
24.8 \\
6.0 \\
11.8 \\
13.5 \\
12.4 \\
0.2\end{array}$ & $\begin{array}{l}(3.0) \\
(5.0) \\
(1.4) \\
(3.8) \\
(3.1) \\
(4.2) \\
(0.1)\end{array}$ & $\begin{array}{r}27.4 \\
25.1 \\
9.9 \\
12.4 \\
14.8 \\
10.2 \\
0.2\end{array}$ & $\begin{array}{l}(3.8) \\
(7.0) \\
(1.7) \\
(2 \cdot 1) \\
(3.6) \\
(3.5) \\
(0.1)\end{array}$ & $\begin{array}{r}27.4 \\
21.3 \\
9.4 \\
15.2 \\
15.4 \\
11.0 \\
0.3\end{array}$ & $\begin{array}{l}(4.8) \\
(0.9) \\
(1.5) \\
(1.0) \\
(1.3) \\
(1.2) \\
(0.1)\end{array}$ \\
\hline
\end{tabular}

MDI-Metered dose inhaler.

pharynx, apparatus, exhaled air, and the open part of the spacer is shown in table 2 , and typical deposition patterns are shown in figure 2. Deposition in the whole lung was significantly greater with both fast and slow inhalation via the spacer than with the metered dose inhaler alone ( $p<0.05$ ). Deposition in the oropharynx was less with the spacer than with the standard metered dose inhaler $(p<0.05)$, though deposition on the apparatus was greater $(p<0.05)$. Significantly more aerosol was deposited in the oropharynx with fast than with slow inhalation through the spacer $(p<0.05)$.

Deposition patterns with slow inhalations (via both metered dose inhaler and spacer) were significantly more peripheral than with fast inhalation via the spacer $(p<0.05)$, the mean (SEM) ratio of peripheral zone activity to central zone activity being $1.37(0 \cdot 13)$ for inhaler alone, $1.34(0.11)$ for spacer with slow inhalation, and $0.81(0.13)$ for spacer with fast inhalation. There was a trend towards a greater percentage

Table 2 Mean (SEM) percentage of the drug dose delivered to various sites

\begin{tabular}{|c|c|c|c|c|c|c|}
\hline \multirow{4}{*}{$\begin{array}{l}\text { Whole lung } \\
\text { Peripheral lung } \\
\text { Oropharynx } \\
\text { Actuator and spacer } \\
\text { Losses from open } \\
\text { part of spacer } \\
\text { Exhaled }\end{array}$} & \multirow{2}{*}{\multicolumn{2}{|c|}{$\frac{M D I}{\text { Slow flow }}$}} & \multirow{2}{*}{\multicolumn{2}{|c|}{$\frac{\text { Spacer }}{\text { Slow flow }}$}} & \multirow{2}{*}{\multicolumn{2}{|c|}{$\frac{\text { Spacer }}{\text { Fast flow }}$}} \\
\hline & & & & & & \\
\hline & $\begin{array}{r}11 \cdot 0 \\
4.7 \\
75 \cdot 0 \\
13.9\end{array}$ & $\begin{array}{l}(1 \cdot 4) \\
(0.6) \\
(2 \cdot 5) \\
(1 \cdot 8)\end{array}$ & $\begin{array}{r}16 \cdot 1 \\
6 \cdot 9 \\
31 \cdot 8 \\
46 \cdot 1\end{array}$ & $\begin{array}{l}(2 \cdot 2)^{*} \\
(0 \cdot 9) \\
(1 \cdot 9)^{*} \\
(2 \cdot 8)^{*}\end{array}$ & $\begin{array}{r}13 \cdot 3 \\
4 \cdot 3 \\
44 \cdot 9 \\
40 \cdot 4\end{array}$ & $\begin{array}{l}(1 \cdot 7)^{*} \\
(0 \cdot 5) \\
(1 \cdot 9)^{*+} \dagger \\
(2 \cdot 3)^{*} \dagger\end{array}$ \\
\hline & $\overline{0.2}$ & $(0 \cdot 1)$ & $\begin{array}{l}5 \cdot 7 \\
0 \cdot 3\end{array}$ & $\begin{array}{l}(1 \cdot 1) \\
(0 \cdot 1)^{*}\end{array}$ & $\begin{array}{l}1 \cdot 1 \\
0 \cdot 3\end{array}$ & $\begin{array}{l}(0.4) \dagger \\
(0.1)^{\star}\end{array}$ \\
\hline
\end{tabular}

p values by multiple comparison test: ${ }^{*} p<0.05$ for metered dose inhaler $v$ spacer; $\nmid \mathrm{p}<0.05$ for spacer (slow flow) $v$ spacer (fast flow) MDI-metered dose inhaler. 


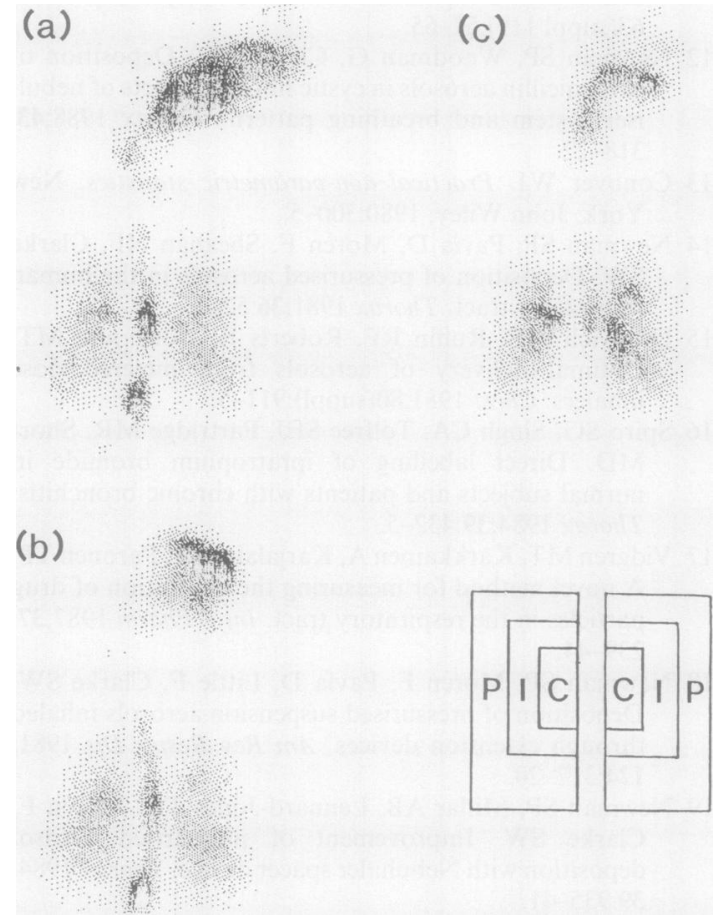

Fig 2 Typical deposition patterns of radioaerosol in one subject (a) for metered dose inhaler alone, (b) for spacer with slow inhalation, and (c) for spacer with fast inhalation. The inset shows the division of the lung fields into central $(C)$, intermediate $(I)$, and peripheral $(P)$ zones.

deposition in the peripheral zone (table 2) with slow inhalation through the spacer, but this was not significant. Both total and regional lung depositions were similar for the four non-smokers and for the six smokers.

Inhaled flow rates averaged 26.1 (SEM 4.1) 1/min for the metered dose inhaler alone, $23 \cdot 8(2 \cdot 1) 1 / \mathrm{min}$ for slow inhalations through the spacer, and $105 \cdot 3(11 \cdot 7)$ $1 / \mathrm{min}$ for fast inhalations through the spacer. Inhaled volumes were similar for the inhaler alone $(2.07(0.31)$ 1) and for slow inhalations through the spacer (2.05 $(0 \cdot 31) 1)$, but were higher for fast inhalations through the spacer $(2.73(0.32) 1)$.

\section{Discussion}

The distribution of aerosol between lungs (mean $11.0 \%$ ), oropharynx, actuator, and exhaled air was similar to that observed previously in our laboratories for a correctly used metered dose inhaler when particles of Teflon, labelled with ${ }^{99 m} \mathrm{Tc}$, were inhaled from pressurised canisters containing placebo. ${ }^{114}$
Other radiotracer techniques have given a similar fractionation of the dose. ${ }^{15-17}$ The technique used in this study is a simpler method of labelling metered dose inhalers than the use of Teflon particles, requiring less specialised equipment, and the measurements reflect actual drug deposition rather than the deposition of an inert analogue. There was a close correlation between quantities of drug and radiolabel in different size bands, so that the radiolabel acted as a marker for the presence of the drug. The method was developed from that of Köhler et al, ${ }^{8}$ who extracted ${ }^{99 m} \mathrm{Tc}$ as ${ }^{99 m} \mathrm{TcO}_{4}^{-}$out of the aqueous phase with ethyl methyl ketone, and makes use of the greater solubility of ${ }^{99} \mathrm{TcO}_{4}^{-}$in micronised drug than in either surfactant or propellant. The addition of radiolabel had little effect on the distribution of drug within the impinger system by comparison with an untreated canister.

The use of the open spacer device reduced oropharyngeal deposition as observed previously with other models of spacers or holding chambers. ${ }^{18-21}$ Oropharyngeal deposition was higher with fast inhalation through the spacer, as has been observed with inhalation from a metered dose inhaler alone," but this was compensated for by smaller losses on the apparatus and from the open part of the spacer. Whether inhalation through the spacer was fast or slow, deposition in the lungs was greater than after an inhalation from a metered dose inhaler alone with a slow inhalation. Several studies looking at other devices have shown that when similar inhalations are made through a metered dose inhaler and a spacer plus metered dose inhaler deposition in the lungs is enhanced with the latter. These have included studies on a $10 \mathrm{~cm}$ tube extension to the inhaler mouthpiece, ${ }^{22}$ a $750 \mathrm{ml}$ cone shaped spacer (Nebuhaler) ${ }^{1922}$ and a $600 \mathrm{ml}$ collapsable spacer (InspirEase). ${ }^{2022}$

The more central deposition patterns within the lungs observed with fast inhalation through the spacer (despite the fact that these fast breaths were also inhaled more deeply) are in agreement with measurements using either polystyrene particles ${ }^{23}$ or iron oxide particles ${ }^{24}$ inhaled by tidal breathing, as impaction in large central airways is enhanced with fast inhalation. The more central deposition was countered, however, by better delivery to the whole lung than with a metered dose inhaler alone, so that the percentage of the dose in the peripheral lung zone was not reduced. Deposition patterns in patients with obstructive airways disease might differ from those observed here in normal subjects, though Spiro et al ${ }^{16}$ found similar total and regional depositions of pressurised aerosol in the lungs of normal subjects and patients with chronic bronchitis.

The "open" spacer differs from most other spacers currently available, because it is not possible to fire the spray into the spacer and to inhale the contents of the 
spacer subsequently. Good coordination is essential with the open spacer to prevent loss of the entire dose, though a small percentage of the dose appears to be always lost from the spacer even during coordinated inhalations, particularly those at a slow flow rate. The open spacer may prove useful for teaching correct use of a sodium cromoglycate inhaler; once coordination with the spacer has been mastered, whole lung and peripheral lung deposition at least as great as those from a correctly used metered dose inhaler may be attained irrespective of the speed of inhalation. Rapid inhalation is a common error when a standard metered dose inhaler is used, ${ }^{25-27}$ resulting in reduced drug delivery $^{11}$ is and clinical efficacy ${ }^{2829}$; but the open spacer appears to permit fast inhalation. The current study was performed in normal subjects, however, and further studies in asthmatic patients are required to determine more precisely the role of the open spacer in clinical practice.

We would like to thank Dr D Köhler for his help and advice, and in particular for his willingness to supply a preprint of his paper on aerosol delivery from metered dose inhalers. We are also grateful to $\mathrm{Mr}$ B Patel for performing the statistical analysis.

\section{References}

1 Godfrey S. Anti-allergic agents. In: Clark TJH, Godfrey S, eds. Asthma. London: Chapman and Hall, 1983: 359-71.

2 Lindgren S, Bake B, Larsson S. Clinical consequences of inadequate inhalation technique in asthma therapy. Eur J Respir Dis 1987;70:93-8.

3 Coady TJ, Stewart CJ, Davies HJ. Synchronisation of bronchodilator release. Practitioner 1976;217:273-5.

4 Crompton GK. Problems patients have using pressurised aerosol inhalers. Eur J Respir Dis 1982;63(suppl 119): $101-4$.

5 Crompton GK. Inhalation devices. Eur J Respir Dis 1982; 63:489-92.

6 Woodcock A. Training aid for pressurised inhalers. $\mathrm{Br} J$ Dis Chest 1980;74:395-7.

7 Altounyan REC, Cole M, Clark AR. Evaluation of an open spacer for sodium cromoglycate [abstract]. Eur $J$ Respir Dis 1983;64(suppl 126):540.

8 Köhler D, Fleischer W, Matthys H. New method for easy labelling of beta-2 agonists in the metered dose inhaler with Tc99m. Respiration 1988;53:65-73.

9 Few JD, Short MD, Thomson ML. Preparation of Tc99m labelled particles for aerosol studies. Radiochem Radioanal Lett 1970;5:275-7.

10 Bell JH, Brown K, Glasby J. Variation in delivery of isoprenaline from various pressurised inhalers. $J$ Pharm Pharmacol 1973;25(suppl):32-6P.

11 Newman SP, Pavia D, Garland N, Clarke SW. Effects of various inhalation modes on the deposition of radio- active pressurised aerosols. Eur J Respir Dis 1982; 63(suppl 119):57-65.

12 Newman SP, Woodman G, Clarke SW. Deposition of carbenicillin aerosols in cystic fibrosis: effects of nebuliser system and breathing pattern. Thorax 1988;43: 318-22.

13 Conover WJ. Practical non-parametric statistics. New York: John Wiley, 1980:300-5.

14 Newman SP, Pavia D, Morén F, Sheahan NF, Clarke SW. Deposition of pressurised aerosols in the human respiratory tract. Thorax 1981;36:52-5.

15 Dolovich MB, Ruffin RE, Roberts R, Newhouse MT. Optimal delivery of aerosols from metered dose inhalers. Chest 1981;80(suppl):911-5.

16 Spiro SG, Singh CA, Tolfree SEJ, Partridge MR, Short MD. Direct labelling of ipratropium bromide in normal subjects and patients with chronic bronchitis. Thorax 1984;39:432-5.

17 Vidgren MT, Karkkainen A, Karjalainen P, Paronen TP. A novel method for measuring the deposition of drug particles in the respiratory tract. Int J Pharm 1987;37: 239-44.

18 Newman SP, Morén F, Pavia D, Little F, Clarke SW. Deposition of pressurised suspension aerosols inhaled through extension devices. Am Rev Respir Dis 1981; 124:317-20.

19 Newman SP, Millar AB, Lennard-Jones TR, Morén F, Clarke SW. Improvement of pressurised aerosol deposition with Nebuhaler spacer device. Thorax 1984; 39:935-41.

20 Newman SP, Woodman G, Clarke SW, Sackner MA. Effect of InspirEase on the deposition of metered dose aerosols in the human respiratory tract. Chest 1986 89:551-6.

21 Dolovich M, Ruffin R, Corr D, Newhouse MT. Clinical evaluation of a new demand-inhalation MDI aerosol delivery device. Chest 1983;84:36-41.

22 Vidgren MT, Paronen TP, Karkkainen A, Karjalainen P. Effect of extension devices on the drug deposition from inhalation aerosols. Int J Pharm 1987;39:107-12.

23 Pavia D, Thomson ML, Clarke SW, Shannon HS. Effect of lung function and mode of inhalation on penetration of aerosol into the human lung. Thorax 1977;32:194-7.

24 Lippmann M, Albert RE. The effect of particle size on the regional deposition of inhaled aerosols in the human respiratory tract. Am Ind Hyg Assoc J 1969;30:257-75.

25 Epstein SW, Manning CPR, Ashley MJ, Corey PN. Survey of the clinical use of pressurised aerosol inhalers. Can Med Assoc J 1979;120:813-6.

26 Morén F, Andersson J, Stiksa G. Mode of inhalation of trained and untrained asthmatics using a pressurised aerosol. Respiration 1984;45:56-60.

27 Pedersen S, Frost L, Arnfred T. Errors in inhalation technique and efficiency in inhaler use in asthmatic children. Allergy 1986;41:118-24.

28 Newman SP, Pavia D, Clarke SW. How should a pressurised beta-agonist be inhaled? Eur $J$ Respir Dis 1981;62:3-20.

29 Lawford P, McKenzie D. Pressurised aerosol inhaler technique: how important are inhalation from residua volume, inspiratory flow rate and the time interval between puffs? Br J Dis Chest 1983;77:276-81. 